\title{
Research on Home-based Aged-care Service System in Collaborative City
}

\author{
Yan Gao \\ Yantai Nanshan University \\ Yantai, Shandong, China 265713
}

\author{
Shengqun Wang \\ Yantai Nanshan University \\ Yantai, Shandong, China 265713
}

\author{
Dapeng Cong \\ Yantai Nanshan University \\ Yantai, Shandong, China 265713
}

\begin{abstract}
The aging of population is closely involved with the home-based aged-care construction, which extremely needs the joint participation of government, family, committee, enterprises and social non-profit institutions. This article makes analysis on documentary method and questionnaire method to discuss the problems existing in the operation of home-based aged-care service, attempting to build a collaborative home-based agedcare system based on the government, family, committee, enterprises and non-profit institutions and complete the contents and manners of home-based aged-care service through this system, and further to make the service more scientific and professional. In addition, it puts forward specific improvement of countermeasure and suggestion with respect to the problem how to build a coordination mechanism among the participants in home-based aged-care service.
\end{abstract}

Keywords-aging of population; home-based aged-care; ollaboration

\section{The Connotation of Home-BASEd Aged-CARE SERVICE IN COLLABORATIVE CITY}

The so-called home-based aged-care service in collaborative city, according to the opinion of this article, refers to a multiple aged-care mode, which is realized by the means of the comprehensive application of social network and modern information technology, with national laws and regulations as security and committee as significant service support, in which the elders develop the spirit of ownership jointly with the family, committee, government, cooperation and society, and cooperate among them, so as to integrate the resource of aged-care service into a uniform system, forming the most effective structure to meet the different requirements of home-based aged-care services. Under the cooperation pattern, in order to reduce the production cost of the service and the transformation cost of service objects among different services, the participants form a rationalization relationship and interaction taking the collaboration as soul, the individual elder as the service object, committee as the service platform, the government and family as the service provider and the social organizations and enterprises as the service producer.
A home-based aged-care service evaluation system should be established correspondingly for the evaluation of the homebased aged-care service provider in order to screen out the qualified service providers, due to this kind of aged-care service is a corresponding special field. Strictly assess the relevant qualification of the social organizations and facilitating agencies or arrange personnel to conduct satisfaction survey of the elders who accept services, to assess whether the services meet the requirements of the elders and the provided services are up to the standards.

\section{THE FOUNDATION AND CONDITIONS OF REALIZATION OF THE HOME-BASED AGED-CARE SERVICE SYSTEM IN COLlaborative City}

The home-based aged-care service system in collaborative city, the core of which is "collaboration", is a system engineering, involved government, committee, social organization, enterprises, family and personal, these participants have close connections, interacting and restricting each other, and the service system cannot carry out the function of home-based aged-care depends only one of participants. It is required by the relationship per se that only with good collaboration and close cooperation among the levels, departments and posts, the home-based aged-care service system can run normally [2]. Any node disconnected will affect the whole network and chain; consequently affect the realization of the overall object. Moreover, in order to reach the requirements of mutual collaboration, each participant should base on self-interest principle and reach the effect of larger than 2 to $1+1$ results.

\section{A. Government Transition}

Since the home-based aged-care service system has the characteristics of public goods in certain degree and related markets and social service system in our country underdeveloped, the actively participation and guidance of the government are extremely essential, in particularly the leading function of the government in initial period of construction. Along with the constant perfection and development of the socialist market economy system in our country, the 
government conducts correspondingly repeated reform and innovation of political system, change the role of government bodies, vigorously promote the marketization and socialization of the public services, gradually establish and improve the administrative system reform to adapt the requirement of market economy.

Along with the constant development of the market economy in our country, successively rectify the traditional superincumbent national administrative mode, the conception of the government turns to public service type from control type. The 18th Central Committee of the CPC purposes that thoroughly promote separation of enterprise, public service, commune management from the government administration according to the object of establishing the administrative system of socialism with Chinese characteristics, build the service-oriented government with scientific function, structure optimization, honesty and high efficiency and people's satisfaction. Intensify the public service function of the government, around people's increasing material and cultural needs, focusing on safeguarding and improving people's wellbeing. And strengthen the public finance system, speed up the establishment of the basic public service system to benefit all the people, provide the masses more and better compulsory education, basic medical care, social security and other basic public goods and services, as well as constantly promote the quality of the public service and carry out equalization of public service. Hence, the government allows the effective participation of all social powers in the public goods' production, supplication and the administration field of social public affairs according to the requirements of the development of socialist market economy; accordingly strengthen the society's capacity of taking over after the government functions withdraw.

\section{B. Constant Perfection of the Committee Service Functions}

Committee is the support and service carrier of the homebased aged-care service, in which, the committee is the most acquainted and important living space excluding the family. In recent years, the committee construction obtains outstanding achievements, the function of which constantly strengthens and support facilities constantly improves, including the successive foundation of the committee service centers with functions of messes and medical care, not only provide facility on the elders' life, but also establish a good grounding in the development of home-based aged-care service. Compared with the organization support, this kind of service system allow the elders staying with family and not only can meet the requirements for aged-care, but also keep their original living habits, which is more in favor of the elders to spend their remaining years in happiness and suitable for the reality in our country as well as the requirements of social development[3]. In recent years, along with the high-speed development of the social security, primarily build a social security system frame with complete projects, comprehensively covered, which is based on the social insurance, social assistance and social welfare and take the basic age-care, basic medical care and minimum subsistence guarantee system as the key. However, the current aged-care security system cannot meet the huge aged-care requirements in relation to the status quo of serious ageing of population.

In the practice of western developed countries, they take the committee as the support of home-based aged-care service as well; build various welfare facilities and aged-care service organizations in the committee with services provided by professionals and volunteers directly to the elders' residences regularly and the elders are entitled to various professional services at the aged-care service organizations in the committee.

\section{Alteration of Family Structure}

Since China adopts the comprehensive family planning policy in 1983, the newly born population in our country decreases dramatically and the scale of the family become miniaturization day by day. The Research Report on homebased aged-care services in urban areas of China issued by the office of the national committee on aging in 2008 showed that in the late 80 s to the beginning of 90 s of last century, along with the carrying out of the family planning policy and alteration of the family consciousness, the family compositions trend to miniaturization, one of the most particular phenomenon was the increasing of only child and family average population decrease. The average population of each family in 1982 was 3.1 and in 1995 was 3.7. The sixth population census in 2010 showed that the average population of the family was 3.1, amount of which decreased by 1.3 with descend range up to $29.55 \%$ and the miniaturization of the family structure in urban were more obvious. Along with the parents of first generation of only child of "post-80s" come into agedness, the structure of the only child family present obvious "inverted pyramid type", that is a young couple should take care of four elders. Moreover, along with the alteration of the people's life idea, the development of the social economy, improvement of the housing condition and the parents of only child family enter into old age, the empty nest phenomenon will be more widespread.

Although home-based aged-care is our traditional way of aged-care, along with the alteration of people's life style and mode of living, the miniaturization of the family scale and the speed up of the pace of life as well as the increasing of the work stress, hence the function of the traditional home-based aged-care is weakened enormously so that the responsibility for aged-care cannot be borne by family alone[4]. The homebased aged-care, which is connected with the advantages of family support and organization support, makes the elders enjoy the social service for the aged at home, effectively meet the elders the requirements for aged-care and the emotional sustenance to family, unlikely have the feeling of "aged-care away from home". At the same time, it also reduces the burden of various problems brought to the family. Through making efforts on innovation and taking active actions, the government cooperates with the social organizations, by the means of government purchasing home-based aged-care service, to provide aged-care services. In addition, with the family and elders positive participation, mutual parties make joint efforts to play a better function of home-based aged-care. 


\section{The PRoposal AND ANALYSis ON COLLABORATIVE HOME-BASED AGED-CARE SER VICE CONSTRUCTION}

Start with the role played by the participations of the homebased aged-care and the borne responsibilities, the basic assumption of the collaborative home-based aged-care service system is by government playing the role of macro-control, specifically including the policy-making and capital support, set up the platform for committee services, play a basic role of family, encourage and guide the social forces such as social organizations, enterprises, volunteers and social idle labor forces to take part in home-based aged-care services with mutual coordination, jointly establish a collaborative homebased aged-care service system combine with professionalization, socialization and welfare.

\section{A. The Government}

1) Rules and regulations stipulation, overall planning: The government, which is the constitutor of the public policies and provider of public services, should be responsible for the home-based aged-care services. Hence, the government should clear and definite its responsibility for collaborative home-based aged-care service, completely play a leading role. At first, it should establish and perfect related laws and policies, speed up related legislation on rights for the elderly and committee home-based aged-care; secondly, make a mid-and-long term planning for the development of collaborative home-based aged-care service, change the thoughts and integrate the functions of related government sectors to provide security for home-based aged-care service; at last, the government should attract more social resources and forces into the home-based aged-care services by the means of introducing preferential policies and measures of revenue, credit, land and re-employment, give full play to the functions of various resources through government intervention.

2) Financial support: Draft and implement various preferential policies to promote the development of homebased aged-care services. However, due to the lack of invested capital, there are amounts of service project in the committee home-based aged-care services cannot develop better, not to mention to develop new service projects. Hence, the government should increase the capital support, ensuring well funded, so as to guarantee the normally running of the home-based aged-care service projects.

3) The integration of interior functional departments: Building connection coordination mechanism among various government departments and breaking the prescriptive regulatory barriers, is a urgent task of public management in our country. The development of various specific public services always require for the security of various policies and law institutions and the support of various public management resources, in case of repeated management and vacuum management, the different levels in same department or different departments all should divide reasonably and cooperative with others. In order to make each department surpass the benefit of its own and break the bonds of administrative contents and statuses of various departments, the government should establish institutionalized network governance structure allowing collaborative work among various departments. As a part of the public service, the home-based aged-care service involved in lots of executive functions of departments, such as department of finance, department of insurance, labor department, department of health, industry and commerce department, it is managed by mutual departments for certain[5]. In order to break through the limit of the administrative levels of various departments and the departmental interests as well as realize the government's commitment and a series of consequent administrative supports and financial investment, it is required to build an institutional governance structure with matrix gridding style, forming a cooperation effective among different levels and departments, so as to give a reliable and sustainable security to the various public resources required by home-based aged-care services.

\section{B. Social Organizations}

The realization of high-effective and high-quality homebased aged-service needs more specialized server force than abundant capital supports, which is not processed by the traditional home-based aged-care system or organization support. However, the social organizations can effectively solve the problem of lacking professional team confronted by the home-based aged-care relying on its professional ability, as well as constant development and cooperation with the government to promote the service level of the home-based aged-care. Secondly, the social organizations can collect the capital support for home-based aged-care through its influence, such as donation and foundation support etc to make up the insufficient of government investment [6]. Moreover, the social volunteers, as a special "social organization", are the significant service force of home-based aged-care service. The volunteers can carry out the services of "one helps one" and "more help one" to the housebound elders, after related training, it can effectively remit the situation of short-staffed.

\section{The Enterprise}

The enterprises are the producer of the home-based agedcare, in the specific work of which, the enterprises can use the most cost-effective ways to provide the services and products required by the home-based aged-care service, integrate the resources and provide abundant aged-care services for the requirements of different levels, meeting the different consumer demand of different objects in the committee[7].

\section{The Family and Individual}

As the direct object of the service and beneficiary of the home-based aged-care service, the assessment and supervision of the home-based aged-care service made by the elders are the most impersonal and accurate. Adopt the assessment of the elders and their family into the evaluation system of homebased aged-care service is good to promote the quality of the service and arouse the enthusiasm of the participants as well as the construction of the collaborative home-based aged-care service system. The service provider can know more about the 
requirements of the elders according to the assessment of the elder and their family on the service, providing more suitable services and promote the operation efficiency of home-based aged-care services, avoiding the waste of service resources. Hence, promote the elders' sense of ownership of participation of home-based aged-care service can guarantee greatly the effective and constant running of the collaborative home-based aged-care service for long term. In order to promote the degree of participation of the elders needs to attract the elders' attention and promote their interesting. With the advanced experience from foreign countries, it is required to attract more elders coming into the home-based aged-care services with more abundant service contents, more humanized service form and novel service means [8]. In order to promote the degree of participation of the elders, it is need to increase the publicity of home-based aged-care services for certain, make the elders in both urban and rural areas to know the contents and advantages of the service through committee, newspaper, broadcast, television etc. as well as encourage them to take part. Secondly, the government should strengthen the intensity of innovation, constantly enrich the contents of home-based aged-care service, promote the service quality and allow more elders to take part.

\section{REFERENCES}

[1] Mou Xian. Social Work and Home-based aged-care service in Committee [J]. 2012 (09) (01).

[2] Zhang Ying, Chen Xinde. Research on Construction of Committee Home-based Aged-care Service System in Urban [J]. The World of Labor Guarantee (theory version).2012 (01).

[3] Hu Hongwei, Shi Yuanyuan, Xiao Yixue. The Selection of Aged-care Security Mode and Path in China under the Visual Angle of Equalization of Public Service --- The advantages and development path of home-based aged-care service security [J]. East China Economic Manangement. 2012 (01).

[4] Li Liang. The Researching and Thinking on Committee Home-based Aged-care Service System with the Background of Ageing of Population [J]. Technological Development of Enterprise. 2011 (03).

[5] Han Junjiang, Xu jia. Research on The Status and Countermeasure of Home-based Aged-care Service in Jilin Province. [J]. The World of Labor Guarantee (theory version).2011 (01).

[6] Sun Yan. Socialized Service for the Aged: Practice Pattern of Government, Committee and Social Organization Trilateral Cooperation [J]. Society. 2010 (12).

[7] Hou Zhiyang, Zhang Wenkui. The Committee Service and Committee self-organization capacity: Case Analysis Based on Home-based Agedcare in Urban $[\mathrm{J}]$. The Journal of Foshan School of Science and Technology (Social sciences). 2010 (06).

[8] Wang Yuchen. Home-based Aged-care in Committee to Build a Harmonious Society [J]. The Journal of Shanxin Colleges for Training Managerial Personnel. 2010 (03). 